\title{
Disability and difference: balancing social and physical constructions
}

Tom Koch Hospital for Sick Children, Toronto, Canada

\begin{abstract}
The world of disability theory is currently divided between those who insist it reflects a physical fact affecting life quality and those who believe disability is defined by social prejudice. Despite a dialogue spanning bioethical, medical and social scientific literatures the differences between opposing views remains persistent. The result is similar to a figure-ground paradox in which one can see only part of a picture at any moment. This paper attempts to find areas of commonality between the opposing camps, and thus to rearrange the figures of the paradox at a fundamental level. The purpose is first to identify areas in which common ground can be achieved, and secondarily, to clarify the areas in which disagreement continues. While a general and unified theory of physical differenceldisability is beyond the scope of this paper the result may advance that general goal.

(Fournal of Medical Ethics 2001;27:370-376)
\end{abstract}

Keywords: Bioethics; disability; eugenics; paradox; social construction theory

A classical visual paradox is emblematic of the current debate over the nature and meaning of "disability": a white, goblet-shaped object separates the facing silhouettes of two black cutout profiles. Either the subject sees the goblet or the profiles but never both simultaneously. With some practice a person may alternately perceive either the profiles or the goblet, but to see all components as a simultaneous gestalt is nearly impossible. In this context, the profiles represent the perspective of those who define disability in terms of a social discrimination that limits the opportunities of persons of difference. The goblet represents the "medical model", defining disability as a negative variation from the physical norm that necessarily disadvantages the physically distinct subject's life and life quality.

The differences underlying both perspectives appear to be fundamental. Still, they can be diminished through a careful consideration of both the language and nature of this opposition. The reasons for doing this are manifest. First, it permits areas of substantial agreement to be identified and emphasised. It also creates the possibility of a general synthesis of physically and socially based perspectives, of a paradigm that isn't paradoxical. While a unified theory of disability/difference is beyond this paper, it is hoped that its potential will be advanced through the analysis of these two positions, their areas of commonality as well as their articles of distinction. For simplicity's sake, the focus will be on the recent debate over "disability" between John Harris and others in this journal. As I will show, their disagreements are representative of a greater dialogue occurring across a range of literatures.

\section{Critical values}

Authors arguing a social definition of disability insist the importance of a physical difference lies solely in discriminatory social reaction to or ignorance of the effects of that difference. ${ }^{1}$ It is the reaction to these conditions, not the inherent limits they may impose, that are their signal feature. Advocates of this position typically see themselves in opposition to those advancing a "medical model" which defines disability as the presence of a physical or cognitive difference that deviates negatively from a "mundane" norm. ${ }^{2}$ For purposes of identification, in this paper the former are called "social difference" advocates or theorists while the latter are referred to as clinical or medical model proponents.

To use the language of Goffman, proponents of a clinical model, like Harris, are perceived by their critics as focusing upon the "stigmata," the appearance of a physical diffrence, one presumed to be unaesthetic and undesirable. Social difference advocates, for their part, take as their focus the social reaction to that signal difference. ${ }^{3}$ Issues of functional impairment, or the compromise of interests potentially resulting from a clinically observable physical limit, are, from their perspective, unimportant outside the social response to those conditions. Indeed, social difference theorists typically reject the idea that physical difference may necessarily compromise the affected person's interests. For them, "dis-ability" only results when 


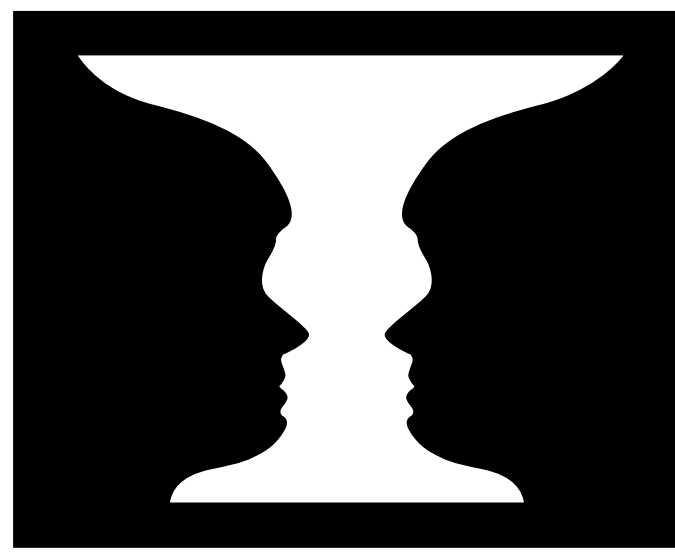

Figure 1: The visual paradox of profiles and goblet

physical difference is not accommodated by society at large.

This opposition can be seen in an extended discussion about, for example, the World Health Organization's (WHO) physically grounded definition of disability, and the means by which issues of social and physical difference are to be studied. In the former, the WHO's primary allegiance to a clinical model, and only secondarily to issues of discrimination, is challenged by those who insist that social prejudice rather than physical distinction is the heart of the matter. ${ }^{4}$ In a social scientific vein, the opposition is continued in the debate about what some have called the "disability paradox". If life quality is assumed to be dependent on physical wellness and independence, the reported positive life quality of physically restricted, dependent persons is seen, by at least some proponents of a physical model, as paradoxical. ${ }^{5}$ For medical ethicists and members of the greater community alike, the stakes are high. At issue are policies and approaches to people with chronic differences, and increasingly, future generations of persons who may inherit them. If physical differences are defined as negatives, then a eugenic selection for normalcy makes sense. From this perspective, Harris notes, eugenics is not a pejorative but instead a logical attempt to assure the "production of fine offspring" through abortion or positive genetic selection." Social difference advocates also see the leap as a logical next step for advocates of a clinical definition of disability. They, however, perceive the potential for eugenic selection as dangerous and ill advised. ${ }^{6}$

Given that by conservative estimates at least 13 million persons in the United States alone are affected adversely by genetic conditions, the potential effect on future generations is vast. ${ }^{7}$ Depending on one's perspective, whole communities of persons at risk to one or another genetically defined disorder - achromatopsia, ${ }^{8}$ familial Alzheimer's disease, Down's syndrome, Huntington's chorea, etc-will be affected by this debate. At least in
North America eugenic pruning, preventing the birth of those with disorders that can be diagnosed prenatally, today appears to be the default judgment on the part of many medical professionals, including bioethicists, and the general public. In a US study, for example, adults with neurofibromatosis 1 reported a consistent argument for abortion and against procreation by their genetic counsellors and physicians. ${ }^{7}$ In Canada, bioethicists at one hospital reported parents were likely to choose abortion when amniocentesis showed an otherwise normal fetus would be born with surgically correctable cleft palate and harelip. ${ }^{9}$ More generally, a recent US study reported upon a demographically diverse survey in which women questioned stated that the risk of a test procedurerelated miscarriage was justified when compared with the possibility of having a child with Down's syndrome. ${ }^{10}$

In a broader frame, the physical disability/social difference debate reflects a growing dialogue about definitions of humanness and personhood. The medical model assumes (as do most bioethicists) that autonomy and self sufficiency are defining elements of the "normal" human condition. It is the standard against which the lives of those with limiting conditions are typically measured. People whose physical or cognitive makeups limit autonomy and self sufficiency are assumed to face "a limitation within the individual" ${ }^{11}$ that prevents them from enjoying pleasures or undertaking tasks available to the average individual. Those lives are assumed to be less happy, their life quality therefore less full, and their continuation, as a consequence, less desirable.

Social difference theorists insist that a physically dependent or interdependent life is no less full and viable than one that is autonomous and independent. Differences that may exist are inherently trivial except to the extent they reflect social prejudice or indifference. More fundamentally, some argue the assumption of independence and self sufficiency as a norm is itself reflective of prejudice rather than reality. As Nussbaum noted in a recent article: "the relative independence many of us enjoy looks more and more like a temporary condition, a phase of life that we move into gradually, and which we all to quickly begin to leave". ${ }^{12}$

If self conscious, self sufficient autonomy-the ability independently to choose to pursue any activity without regard to physical limit - is at best a temporary phase in the normal life course, then "disability" becomes not a negative deviation from the norm but as normal as childhood and old age. Once revealed, "the fiction of competent adulthood," as Nussbaum calls it, masks the recognition of physical restriction and dependence as a normal, not a deviant state within the life course. ${ }^{12}$ Disability becomes, in this construction, a matter of degree and timing, not an aberration.

Certainly there is a difference, advocates of the medical model argue, between limits resulting from accident, age, or injury and those that affect a person from birth. The latter are not the norm 
and should, clinical model advocates assume, be avoided if possible. Harris, for example, argues that the inability to hear is obviously a disability whose inheritance presents a real harm to future generations. Many congenitally deaf persons argue, however, that their physical reality does not represent an inherent and unacceptable limit. An inability to hear sounds-or to communicate verbally-is a fact (like skin colour) without significance in the weighing of their existential reality. The richness of sign language assures communication and the only real problem, to deaf activists, is the refusal of many in the hearing world to see them as equals. For them, deafness represents a community built around shared language and experience.

This is not to deny the claim of the hearing normal that hearing good music, a great symphony, perhaps, may be one of life's great pleasures. Nor, by extension, does it refuse the claim of those with normal vision that it is satisfying and enriching to see a beautiful landscape or a great painting. Rather, the deaf activists - and by extension the social difference advocates generally-argue these are not necessary pleasures whose failure diminishes the human experience. One may acknowledge the joy they bring others without insisting that the inability to perceive them is a harm or deficit. After all, many persons are "deaf" to the pleasures of classical music (or jazz, or reggae, or rap, etc) and yet none assume their limits of comprehension reflect a deficit or harm. Others are "blind" to the beauty of classical painting (or, perhaps, to abstract expressionism) and are not considered disabled. Insisting upon harm and limit is to deny, social difference advocates insist, the diversity of perceptual experience and personal taste that exists among human beings generally, and within individuals across the life course.

While the debate about the significance of congenital deafness has been one of long standing, ${ }^{13}$ it masks the degree to which hearing loss is a normal if often difficult aspect of the adult ageing process. Not only do many develop hearing loss through accident and injury (in childhood or as adults), acuity typically diminishes as part of the general aging process. It is "normal" for those in their seventies-and certainly their eighties-to lose the ability to perceive higher tones; many if not most require hearing aids and other assisting devices. Is this a "harm" resulting from the aging process or simply a fact of continuance whose effect is socially construed?

At the least, the possibility of physical difference as a fact of longevity requires those who adopt a medical model of disability to consider shadings and degrees of difference in their construction. An either/or paradigm in which one is normal or disabled is inadequate to conceptualise the diversity of ability within the greater population, and across the individual life course. Between "deaf" and "hearing" is a range of potential limitations; between "blind" and "normally sighted" is a spectrum of perception. Some loss may be inherent in the life course-presbyopia, for example-some are not.
Persons with strabismus, an inherited neuromuscular disorder, often lose acuity in one eye during early childhood. Even those with sight in both eyes often will not develop binocular vision, and thus are without normal depth perception. And yet, persons with strabismus are rarely labelled as "disabled". Thus the mere fact of a clinically measurable physical limit is insufficient to permit a distinction based solely on that fact. Certainly, as I argue later, the mere fact of an inherited condition is insufficient in itself to permit an informed and ethical endorsement of eugenic planning.

\section{Harmful limits}

The traditional, physical definition of disability used in the clinical model typically refers to a necessarily limited, restricted state in which the subject cannot independently undertake specific tasks or actions. As Harris put it: "It is just that there are pleasures, sources of satisfaction, options, and experiences that are closed to him. In this lies their disability" ${ }^{11}$ This creates a situation, he continues, that is "inherently harmful to the person in that condition and that consequently that person has a strong rational preference not to be in such a condition". Here is the crux of the matter: does physical difference necessarily result in harm; does it necessarily diminish the resulting life?

Clearly there are limitations to the opportunities the average person enjoys. The deaf do not enjoy music; the blind cannot appreciate visual arts. A tetraplegic will never know the pleasure of the long distance runner, pounding along in the endorphininduced runner's high for miles. The validity of the apparently obvious assumption that the person of difference "has a strong rational preference not to be in such condition" is, as I will show, unclear. ${ }^{14}$ Nor is it obvious whether such differenceswhatever the preference of the persons involvedare inherently "harmful".

Unlike other activists who wholly reject the medical, clinical model in favour of a purely social construction, I do not dispute the reality of physical difference. As a person with moderate sight impairments I cannot fly an airplane; cannot safely drive an automobile. My visual limits do not permit me to play baseball, hockey, tennis, etc. I am thus literally dis-abled in relation to those activities. While I might wish to be as farseeing as Nathaniel Hawthorne's character, Hawkeye, I am more like the singularly near-sighted cartoon character, $\mathrm{Mr}$ Magoo. Is this difference, which stems from an inherited genetic condition, important? If it does not necessarily diminish either my life quality or my ability to function in society, I argue, the fact of the impairment is essentially trivial.

Certainly in my case the limits of my inherited condition are insufficient to argue that their passage to future generations would be harmful. A grandchild with my disorder would not, I believe, blame me for the fact of his or her physicality. Certainly I do not take my progenitors to task for this inheritance. My position as a member of society, and as person who can enjoy a range of relations and 
activities, is largely unimpaired by my visual limits. Indeed, learning to live with these limits has been defining in the best sense.

Unable to play baseball, football, or hockey I instead became involved in Japanese martial arts, which has a long tradition of visually challenged adepts. In two arts - aikido and karate-I served as an instructor. While my limits prohibit certain types of activity that affected my life course, a visceral understanding of physical limits has empowered my work with familial caregivers of the elderly, and more generally, persons going through a range of social and physical crises. ${ }^{15}$ Like many with moderate visual limits, my hearing has become acute and I often wonder at the failure of normally sighted persons to hear what to me is a rich and varied, audible texture to the world.

The choices resulting from accommodations to my visual restrictions are so integral to the pattern of my life - so "embedded," to use Stephen G Post's phrase $\mathrm{e}^{16}$ - that I cannot imagine being without them. Were my partner currently pregnant and given the choice of a fetus with my genetic pattern or one that was "normal" I would likely choose the former. Like those in the deaf community who perceive their difference as so integral to their being as to be "necessary," mine has been not so much challenged as channelled by my physical reality. The life resulting from my modest differences more than compensates for the limits inherent in my physiology. To argue otherwise would be to deny the life I've lived.

While I have argued personally here, there is an evolving literature that suggests my experience is not uncommon. Many with genetically inherited conditions view the potential of genetic culling, for example, with mixed emotions. Raised within families - and sometimes communities-where their condition is common, the potential for its future elimination entails as well the end of a link critical to their associative world. This is true of both those with chronic non-progressive conditions such as colour blindness (achromatopia) ${ }^{17}$ and those with chronic-progressive diseases such as Huntington's. While some researchers have reported an increase risk of suicide among those testing positive for the Huntington's gene, a comprehensive study of the reaction to genetic testing by persons in Huntington's families revealed a sense of loss among some who tested negative for the mutation associated with Huntington's disease. ${ }^{18}$ For some, their lives had been built upon an expectation of the disease's onset and its absence required a new perspective outside that of the historical community in which they had matured.

More generally, social advocates critical of the medical model argue that many persons with physical differences describe unexpected areas of accommodation that they insist are more than compensatory. ${ }^{19}$ Almost universally, these include an increased richness in interpersonal relations and an acceptance of physical dependence as an acceptable quality of human intercourse. This literature acknowledges the physical limits but finds social and interpersonal values in the resulting life. Thus what disability protagonists perceive as, in Harris's words, "inherently harmful", may not be for the subject him- or her-self inherently anything. It becomes a fact of one's history-an aspect of one's physical embeddedness - and accepted or rejected precisely as one may reject or accept any life change. From this perspective, Harris's definition of a disabling and thus necessarily harmful condition becomes suspect.

But-and here I believe those advancing a clinical perspective are correct - this does not mean the physical difference is meaningless. A part of the Harris definition of disability is that it reflects a condition that the person affected would express "a strong rational preference not to be in ...”. Many I know and sometimes counsel who have chronic progressive conditions such as multiple sclerosis would be delighted if normalcy could be magically restored. It does not necessarily follow from this, however, that the prospect of physically differentiating conditions can be used easily in defining physical difference as a wholly disadvantaged state. It is one thing to acknowledge the reality of a physical condition, another to argue its harm is so great as to diminish the affected life. Physical limits may change a life without necessarily resulting in an insupportable life quality.

What to outsiders may seem to be an unacceptably restricted life is often, for those who live it, filled with meaning. ${ }^{20}$ Persons with physical and perceptual differences may daydream of a full physical range of activity - as the weekend athlete dreams of being an Olympic medallist - but this does not mean they believe their existence is necessarily burdensome or lacking. To argue a necessary harm without reference to this experiential literature $^{21}$ is to insist that one's own sense of normalcy should rule, irrespective of the evidence of those perhaps best situated to judge the life quality that results from physical difference.

\section{Social factors}

Harris argues - as do others who present a clinical perspective - that "we must separate the question what is of use to existing disabled people from the question of what constitutes disability and the ethics of minimising its occurrence in the future" ${ }^{2}$ The failure of many social difference advocates to acknowledge this suggestion affects the broad acceptance of their position. Many who, like Harris, argue from a medical model of disability do so with a profound distaste for the contemporary continuation of historical patterns of social discrimination. To separate clearly the condemnation of discriminatory practices from the greater problems of definition, especially as they apply to future generations, would be to create a stronger coalition of persons active and vigilant in addressing discriminatory practice today.

It is therefore useful, perhaps, to adopt Riccardi's distinction between "superimposed" conditionsthe physical effect of this or that physical condition - and the "responses" to it by society at 
large. ${ }^{22}$ This construction effectively acknowledges both the fact of the former and the effect of the latter. Were it to become a basis for shared discussion, it would permit a general condemnation of discriminatory social realities. As one US researcher recently noted, there is already a strong public desire to avoid discrimination against those who are physically different or chronically ill. $^{23}$ A joint disavowal of discriminatory social responses by both social difference and clinical model advocates would, I suspect, advance a common call for educational enrichment for persons with learning differences; mobility aids for persons with ambulatory limits; visual aids for the visually challenged, and public translators for the deaf, etc.

\section{Eugenics}

Further separating the elements of the debate would permit members of both disability and difference groups to focus more clearly on the essential issues that for some years will continue to divide them. From this perspective, the critical issue to be considered is the wisdom of the eugenic perspective advanced by some clinical model proponents on behalf of future generations. Members of both groups agree, in short, on the need to integrate people of difference into society, to assure them of support and to reject discrimination toward them. The question then becomes whether society should adopt programmes that will limit future generations on the basis of their potential differences.

While it appears true that most persons of difference would avoid extremely limiting conditions (Tay Sachs, for example), it does not necessarily follow that all would agree that passing on most physically limiting conditions to future generations is inadvisable where not actually harmful. To argue for eugenic selection of future generations is to insist the resulting life is inherently inferior solely because of that inheritance. At present it may be difficult for many to separate the effect of social prejudice - and here definitions are again important-from the real physical limits imposed by that inheritance.

As importantly, perhaps, I would argue that our current state of mastery is such that any discussion of eugenic selection is wholly premature. Simply, our current state of knowledge (or ignorance) is sufficient to permit only non-procreation by those with inherited differences or, in the event of pregnancy, termination of the affected fetus. The gene responsible for this or that condition cannot be turned off, leaving the "person" to emerge. We can perform preimplantation genetic testing on embryos, and select genetically unaffected ones, but we cannot engineer the affected embryo so it will be "normal". Nor can the effects of the genetic condition, once identified, be adequately assessed. A fetus with Down's syndrome, for example, may become a "high functioning" person, or one with very low levels of ability. Some might seek to preserve the first but not the second.
In short, even if one accepts the idea of eugenic pruning our tools are at present so gross as to be unlikely to permit anything but a wholesale cutting. Finally, the assumption of future harm as a basis for eugenic selection is difficult to justify and difficult to apply to conditions that may be devastating but have their onset only in adulthood. These include, in a partial list, ALS/MS (amytrophic lateral sclerosis/multiple scleorsis), familial Alzheimer's, Huntington's chorea, etc. To eliminate the person who might develop these conditions in midlife or later would be to deprive society at large of people such as physicist Stephen Hawking (ALS), former US president Ronald Regan (Alzheimer's), or singer Woody Guthrie (Huntington's). It is at best uncertain that late onset is a "harm" such that these persons-or their progeny-would readily accept eugenic pruning as a reflexive option.

Nor is it clear whether society at large would benefit from a programme that prevented their existence. Hawking, for example, has argued that his physical condition has served as a critical impetus to his academic career, which has been marked by a concise style of writing necessitated by his physical limits. ${ }^{24}$ Even if unanimity were achieved in cases of "extreme" and rapidly terminal childhood disorders (multichromatic leukodystrophy, for example), would it extend to those with spinal bifida (or a cleft palate)? To argue "harm" to future generations as a blanket condition without consideration of the precise nature of the harm that results in specific contexts (and at different points in the life course) is dangerous. Given that there are at present over 5700 genetic disorders that have been documented for the human species, where does one draw the line $?^{25}$ The sheer magnitude of the potential to limit birth to those whose genetic profile is "pure" carries the threat of a nightmare search for nothing but "perfect" humans.

Finally, even in the event society could make a consensual determination on which inheritable diseases should be eugenically pruned from the human tree, persons of difference would remain within the community. These would be individuals whose physical limits resulted from injury, or from the manifestation of conditions for which no genetic marker is yet known. The fact of physical difference therefore will remain and, as we puzzle over future generations, it is important that the commitment to people with differences be affirmed, and support for their participation in society be unanimously argued by social construction and medical model advocates together. Unfortunately, the disagreement between social construction and medical model advocates has inhibited a discussion on how best to advance social support for persons of disability today.

\section{Conclusion}

In this brief review the intent has been not only simply to distinguish the gulf separating theorists advancing a traditional, medical model of disability from their critics, but also to emphasise the 
commonalties both groups share. Those critics, most often persons with physical differences, insist the clinical fact of difference is wholly or largely secondary to the social context in which a distinguishing physical condition is accepted or rejected. Members of both groups generally share a commitment to social support for persons of difference who exist among us, and share, too, a desire for egalitarian as opposed to discriminatory practices.

These commonalties are not insignificant. They focus the presently diffuse debate, permitting a more concentrated discussion of specific disagreements while at the same time making possible the presentation of a united front in areas of agreement. In effect, this separates the question of "disability" and "difference" into two parts.

Assuming there is unanimity in support for persons of difference in society, the question then becomes how that support may best be achieved. Secondly, the debate between disability and difference proponents becomes focused upon the issue of future persons whose differences are genetically determinable. This separation is important. To ask whether we should approve the eugenic pruning of the human tree is a different question from whether we should nurture those branches that present themselves to society. In my experience, detailed in The Limits of Principle: Deciding Who Lives and What Dies, members of both the public and the medical communities generally support the extant person of difference, and that person's family. ${ }^{9}$ Advocacy for those who exist with differences thus would presumably be more rather than less inclusive.

An appropriate response to the potential of evolving genetic engineering is less clear. In this arena our ignorance far outweighs our knowledge. It is unclear, for example, at what point a physically acceptable difference becomes a "disability" so extreme as to argue for restriction on the basis of "harm". Nor is it clear whether a determination at this level, even if it could be successfully argued, would apply equally to conditions whose onset is juvenile, adolescent, occurring in mid-life or in seniority. Finally, is the fact of a differenceirrespective of its intensity (Down's syndrome, for example) sufficient to argue a "harm" that justifies prohibition? My suspicion is that our views on these questions will change as our knowledge of genetic science expands.

At the least, were we to accept the general framework outlined here, researchers on both sides of the contemporary debate would find that the difference that separates them-the goblet-would grow smaller as the resulting discourse unfolded. This hopeful prospect would be advanced by joint action over discrimination and the need for social support of persons of difference. Finally, to focus the debate in this manner would permit the greater issues to be highlighted; generally advancing the ethical and social debates that at present are so tangled as to be largely unanswerable. This would enrich the debate on the part of all, without devaluing the views of any.

\section{Acknowledgement}

The author gratefully acknowledges the contribution of assessors whose suggestions, based on the original submission, greatly improved the resulting paper. The comments of Dr Julian Savulescu, offered outside the anonymous peer review process, were especially comprehensive and gratefully received.

Tom Koch, PhD, is a Research Associate in Bioethics at the Hospital for Sick Children, Toronto, Ontario, Canada and Adjunct Professor of Gerontology at Simon Fraser University, Vancouver, British Columbia, Canada.

\section{References and notes}

1 Reindal SM. Disability, gene therapy and eugenics-a challenge to John Harris. Fournal of Medical Ethics 2000;26;89-94; Newell C. The social nature of disability, disease, and genetics: a response to Gilliam, Persson, Draper and Chadwick. Fournal a response to Gilliam, Persson,
of Medical Ethics 1999;25:172-5.

2 Harris J. Is there a coherent social conception of disability? Harris J. Is there a coherent social con
fournal of Medical Ethics 2000;26:95-100.

Fournal of Medical Ethics 2000;26:95-100. 3 Goffman I. Stigmata: notes on the management of spoiled identity. Englewood Cliffs, NJ: Prentice Hall, 1963.

4 World Health Organization. The international classification of impairments, activities, and participation: a manual of dimensions of disablement and functioning. Geneva: World Health Organization, 1997; Üstün TB, Mickenbach JE, Badley E, Chatter S. A reply to David Pfeiffer: "The ICIDH and the need for its revision". Disability \& Society 1998;13:829-83; Pfeiffer D. The ICIDH and the need for its revision. Disability \& Society 1998; 13:503-623;

5 Alrecht GL, Devlieger PJ. The disability paradox: high quality of life against all odds. Social Science and Medicine 1998;48:97788; Koch, T. The illusion of paradox: commentary on Alrecht GL, Devlieger PJ. Social Science and Medicine 2000;50:757-8. 6 GLe reference 1: Reindal SM.

7 Ablon J. Living with genetic disorder: the impact of neurofibromatoAblon J. Living with genetic disorder: the impact of
sis 1. Westport, CT: Auburn House, 1999: ix.

sis 1. Westport, CT: Auburn House, 1999: ix.
8 Sacks O. The island of the colorblind. NY: Knopf, 1997.

8 Sacks O. The island of the colorblind. NY: Knopf, 1997. Koch T. The limits of principle: deciding who lives
Westport, CT: Praeger Publishing, 1998: 113 .

10 Kuppermann M, Nease RF, Learman LA. Procedure-related miscarriages and Down-syndrome-affected births: implications for prenatal testing based on women's preferences. Obstetrics $\mathcal{E}$ Gynecology 2000; 96:511-16

11 See reference 2: 97 .

12 Nussbaum M. Disabled lives: who cares? New York Review of Books 2001 Jan 11. Accessed 14 Jan. 2001 at http:// www.nybooks.com/nyrev/ WWWfeatdisplahy.cgi?2001011023R\#top.

13 Sacks O. Seeing voices: a journey into the world of the deaf. Los Angeles: University of California Press, 1989.

14 See reference 2: 98 .

15 Books and articles in these areas are listed on my website, http://kochworks.com

16 Post SG. Inquiries in bioethics. Washington, DC: Georgetown University Press, 1993: 3-4.

17 See reference 8: 42 and 219

18 Bird TD. Outrageous fortune: the risk of suicide in genetic testing for Huntington Disease. American fournal of Human Genetics 1999;64:1292-9; Cox S. It's not a secret but ... predictive testing and patterns of communication about genetic information to families at risk for Huntington disease. $\mathrm{PhD}$ dissertation, The University of British Columbia, Vancouver, BC, 1999.

19 Koch T. Life quality vs the 'quality of life': assumptions underlying prospective quality of life instruments in health care planning. Social Science \& Medicine 2000;51:419-28.

20 For a review of this literature see reference 19 . For a more detailed survey of the perspective of persons living with chronic conditions see Koch T. Future states: testing the axioms underlying prospective, future-oriented, health planning instruments. Social Science E Medicine 52:3; 2001; 52:453-66. 
376 Equality and disability symposium: Disability and difference: balancing social and physical constructions

21 Young JM, McNicoll P. Against all odds: positive life experiences of people with advanced amyotrophic latera sclerosis. Health and Social Work 23:1; 1988;23:35-43; Sacks O. The man who mistook his wife for a hat. NY: Summit Books, 1984. For a general review of this literature, see reference 19.

22 Riccardi VM. Neurofibromatosis: phenotype, natural history, and pathogensis. Baltimore: Johns Hopkins Press, 1992: 95. See also reference $7: 17-18$
23 Ubel PA. Pricing life: why it's time for health care rationing. Cambridge, MA: MIT Press, 2000. For a review see Flick L. A review of pricing life. Cambridge Quarterly for Healthcare Ethics 2001;10:214-18.

24 Hawking S. Black holes and baby universes. NY: Bantam Books,

25 Bobinski MA. Genetic and reproductive decision making. In: Murray TH, Rothstein MA, Murray RF, eds. The human genome project and the future of health care. Bloomington, IN: Indiana University Press, 1996: 80. 